\title{
Understanding Links Between Social Media Use, Sleep and Mental Health: Recent Progress and Current Challenges
}

\author{
Holly Scott ${ }^{1} \cdot$ Heather Cleland Woods ${ }^{1}$
}

Published online: 13 July 2019

(C) The Author(s) 2019

\begin{abstract}
Purpose of Review Sleep and mental health researchers are increasingly recognising the need to update our approaches to understanding the unique social, emotional and cognitive aspects of social media use, rather than simply considering it as just another hour of total daily "screen time". In this review, we highlight some recent developments in this area, discuss ongoing challenges facing this field and offer recommendations for future steps.

Recent Findings The sleep and mental health research literatures have made recent advances towards a more nuanced understanding of social media use: moving beyond a focus on simply duration of use, towards new insights into the role of content, context and experience of these online interactions.

Summary As this research area moves forward, a focus on high-quality measurement — combined with collaborative multidisciplinary approaches that triangulate insight from different methodologies and perspectives - can inform a more holistic understanding of sleep and mental health in today's connected world.
\end{abstract}

Keywords Sleep $\cdot$ Social media $\cdot$ Mental health $\cdot$ Technology $\cdot$ Screen time

\section{Introduction}

Over recent decades, sleep and mental health researchers have followed changes in the media landscape, examining associated outcomes for prevalent forms of electronic media use: from TV viewing to video gaming to smartphone use $[1 \bullet, 2 \cdot$, 3-6]. Currently, the increasing connectivity offered by devices and platforms has facilitated not only increased time devoted to these media activities, but also important shifts in social norms and expectations around availability and etiquette for online interactions [7-9]. Therefore, social media use is receiving increasing attention independent from other forms of electronic media use, with researchers calling for improved understanding of its unique social, emotional and cognitive aspects in relation to sleep and mental health outcomes [10, $11 \bullet \cdot, 12,13 \bullet \cdot, 14]$. At this juncture, it is important to step back

This article is part of the Topical Collection on Sleep and Technology

Holly Scott

h.scott.1@ research.gla.ac.uk

1 School of Psychology, University of Glasgow, 62 Hillhead Street, Glasgow G12 8QB, UK and survey the current state of this research field, acknowledging developments to date and identifying priorities as we move forward. In this review, we highlight some key developments in this research literature in the last 5 years, discuss ongoing challenges facing researchers in this field and offer recommendations for future steps.

\section{Social Media, Sleep and Mental Health: a Constantly Evolving Landscape}

Concerns about the well-being implications of media use are not a new phenomenon [15•]. However, we must ensure that - as media devices and habits continue to evolve-we too continually update our approaches as researchers and practitioners to understanding their implications for sleep and mental health. Compared with other forms of technology or traditional media, social media platforms facilitate unique changes not only in how we spend our time but also crucially in how we interact with each other. Platforms are easily accessible via smartphone apps (facilitating engagement throughout the day and alongside other activities) and specifically designed to keep users engaged, with continual notifications and no clearly defined end point $[10,16]$. Importantly, platforms provide richly varied opportunities for social 
interactions, allowing individuals to curate a careful selfpresentation through public profiles, quantify peer approval through number of likes and retweets and extend daytime face-to-face peer interactions with $24 / 7$ availability for individual and group messages [7, 17]. Together, these features and user experiences contribute not only to increased time devoted to social media use [18], but also importantly to evolving social norms around expected availability and the urgency of online interactions $[7,8,19]$, presenting unique implications for mental health and sleep.

Alongside this evolution of social media habits and norms, we have seen concurrent developments in our understanding of - and approach to treating - sleep problems. As of 2013, the DSM-5 (Diagnostic and Statistical Manual of Disorders, Fifth Edition) classification of sleep-wake disorders has moved towards recognising the "bidirectional and interactive effects between sleep disorders and coexisting medical and psychiatric illnesses" [20,21]. For example, insomnia is now classified as comorbid with-rather than secondary to - a mental health diagnosis. Researchers and practitioners are therefore updating their approaches to understanding and treating sleep and mental health as two inextricably linked aspects of health, which together present a significant and well-recognised social, economic and health burden internationally [22-24]. It is therefore timely to consider current progress and next steps in ensuring that this developing area of research and practice also incorporates an up-to-date approach to understanding the role of social media: one which encompasses the relevant social, emotional and cognitive aspects of social media use, rather than simply considering it as just another hour of total daily "screen time" [15•].

\section{Approaches to Social Media Use in Sleep and Mental Health Literatures to Date}

In this section, we briefly consider how the sleep and mental health literatures have each tended to approach social media use to date, before considering current developments in each of these areas in the following section.

\section{Sleep Literature's Approach to Understanding Social Media Use}

In the sleep literature, current understanding of social media use has been strongly informed by previous research on traditional media and technology use generally. This approach tends to examine social media use as a technology-based activity, often measuring the frequency, duration and timing of use [25]. Existing reviews of this evidence indicate that social media use-alongside other technology activities like TV viewing, video gaming and computer and smartphone useis generally associated with poorer sleep outcomes, particularly shorter sleep duration and also delayed bedtimes and poorer sleep quality $[1 \bullet, 2 \bullet, 26]$. This body of work has provided a useful framework for understanding the mechanisms by which technology use (including social media use) can impact sleep $[1 \bullet 27 \bullet \bullet]$. These mechanisms include technology use delaying bedtimes and/or interrupting nighttime sleep [28-30], plus screen light potentially delaying circadian rhythms and sleep [31] (for a discussion on integrating evidence on online social interactions and screen light exposure, see Woods and Scott, this issue). It has also been proposed that technology use may impact on sleep by increasing cognitive arousal at bedtime $[1 \bullet, 27 \bullet \bullet, 32]$. Whilst all proposed pathways are relevant for various screen-based technologies (including more passive media consumption), this cognitive arousal mechanism is particularly salient for social media, which offers opportunities for rich social interactions in real time. This highlights the potential added value for sleep literature to further examine social media independently of other technologies, focusing on building a more nuanced understanding of the arousal and sleep-wake implications of its unique social, emotional and cognitive user experiences specifically.

\section{Mental Health Literature's Approach to Understanding Social Media Use}

Interestingly, more of the mental health literature has taken a social interaction perspective - compared with a technology perspective - to understanding social media use. This may explain why the overall evidence on mental health associations is more mixed, supporting both positive and negative outcomes depending on how social media use is operationalised [13*0]. Studies that measure how often and how mисh individuals use social media have reported a mix of significant and non-significant associations with mental health problems [13••, 33], with a large-scale analysis indicating that this digital screen time accounts for very little variance in adolescent well-being [34]. This reinforces the argument that examining only frequency and duration of use is not sufficient to understand the complex links between individuals' social media practices and mental health. Instead, in their 2016 systematic review of available evidence, Seabrook and colleagues stressed that associated (positive or negative) mental health outcomes depended strongly on a range of protective and risk factors around how users engaged with social media [13••]. These include perceived and actual levels of online social support [35-37], and the valence of individuals' social media content, interactions and social comparisons [38-40]. In the following section, we discuss key insights that have been gained in recent years from this approach to examining relevant social and emotional aspects of social media engagement and their implications for both sleep and mental health. 


\section{Current Developments in Research Literature}

\section{Sleep Research: Moving Beyond Hours per Day on Social Media}

Building on a perspective of social media within a technology use framework, much sleep research has examined how the duration, frequency and timing of individuals' social media activity relate to sleep outcomes. These findings have supported links between higher overall social media use and poorer sleep outcomes, including shorter sleep duration, later bedtimes and poorer sleep quality $[17,26]$. The timing of use is highly relevant for sleep, as social media use at bedtime is a strong predictor of poorer sleep outcomes, independent of overall use [14, 16, 17, 41, 42]. These findings are consistent with a sleep displacement mechanism $[1 \bullet, 27 \bullet \bullet, 28]$, as there are only $24 \mathrm{~h}$ in a day, and an hour devoted to any activity (including using social media) is an hour that is spent awake. It is important to note, however, that studies are primarily crosssectional, and the question of causality remains (we discuss this further under "Current Issues and Challenges Facing Researchers" below).

This insight gained from studying frequency, duration and timing is informative for understanding social media use as an activity that may displace sleep. However, to meaningfully inform clinical practice and wider policy, it is crucial to remember that conceptualising social media use in minutes and hours only gives one part of the picture. It is important to consider the wider context around this time spent using social media, to avoid oversimplification in policy and practice that reduces "social media use" from a complex range of experiences and social interactions to a single number (represented only in hours per day). This has been one area of development in the sleep literature over the last 5 years, with more studies examining not only the time that participants spend using social media, but also their experiences of - and motivations for-these interactions [8, 12, 17, 38]. Therefore, alongside the behavioural component (actual social media activity), current understanding of mechanisms linking social media use to sleep has been improved by considering social, emotional and cognitive components of users' experiences.

For example, individuals who spend the same time using social media each day (or night) can differ in the level of emotional connection that they feel towards this activity [25]. Young people in particular often report feelings of disconnectedness and missing out without access to social media and prefer to keep their phones within close reach during the night [43]. This has implications for sleep outcomes, as highly invested users report poorer sleep quality and may find it more difficult to disengage from social media at night [17]. This reinforces the need to consider social media use within the broader context of an individual's online and offline social interactions, as a strong connection to social media platforms can stem from a more pervasive anxiety about potentially missing out $[8,44]$. This underlying fear of missing out has been linked to shorter sleep duration via both a behavioural pathway (by driving late night social media use, which delays bedtimes) and a cognitive pathway (by increasing pre-sleep cognitive arousal, thus further delaying sleep onset) [12]. Therefore, individuals who are concerned about possibly missing out may struggle at bedtime to stop not only using social media, but also thinking about possible social media interactions [8]. This is further fuelled by concerns over meeting perceived social expectations for $24 / 7$ online availability and prompt responses [7-9], which may similarly extend social media activity at bedtime and also increase cognitive arousal even once disconnected.

Building on likely mechanisms that are relevant for all forms of technology use - such as increased cognitive arousal from bedtime use $[1 \bullet, 27 \bullet \cdot$ — these insights are developing a more nuanced understanding of the sleep implications of this inherently social and interactive experience. For example, this cognitive-behavioural perspective can inform practical approaches to supporting a healthy balance between social media use and sleep, which should consider underlying concerns in addition to observable behaviours. For clinicians, educators and parents of adolescents, this indicates that focusing exclusively on reducing nighttime social media activity (e.g. by limiting access) is not only challenging to implement [45, 46], but also fails to address other relevant factors, such as underlying concerns and arousal, that persist independent of actual social media activity.

\section{Mental Health Research: Understanding the "Social" in "Social Media"}

This broader perspective on social media use (including its cognitive, social and emotional aspects) is increasingly represented in mental health literature. However, this shift is relatively recent, and there is still a considerable body of work being cited that considers only the duration and frequency of social media use, which has produced mixed findings for mental health outcomes $[11 \bullet \bullet, 13 \bullet \cdot$. Although some studies have linked more time on social media to increased depressive or anxious symptoms [10, 47], some do not find significant associations [48, 49], and others have found positive associated outcomes, such as reduced loneliness [50]. This reinforces the argument that knowing only how much time an individual spends using social media (without further information on context and experiences) is not particularly informative for understanding its implications for any aspect of health and well-being. Therefore, as in the sleep field, similar calls have been made in the mental health literature to examine the content, context and interactivity of social media use, rather than limiting discussions to simply total "screen time" $[10,11 \bullet$, $13 \bullet \bullet, 15 \bullet$. 
In recent years, this line of research has made considerable steps towards a more nuanced understanding, which is now highlighting the crucial role of how individuals engage with social media in determining positive versus negative mental health outcomes $[11 \bullet \bullet, 13 \bullet \cdot]$. Firstly, associations between social media use and mental health and well-being vary in their direction and strength depending on the following: which platforms individuals use, for what purpose and with whom they interact. For example, time spent using image-based platforms like Instagram and Snapchat (but not text-based platforms like Twitter) is associated with decreased loneliness, possibly due to an enhanced sense of intimacy [50]. This benefit applies to individuals who use these image-sharing platforms for the purpose of interacting with other people, whereas those who simply broadcast content actually report increased loneliness [51]. Specifically, it seems that those who use image-based platforms to interact with people they know personally are not at risk for negative consequences, whilst those who view and interact with image-based content from strangers are more likely to engage in negative social comparisons and have depressive symptoms [52].

Furthermore, in addition to knowing who an individual is interacting with, crucially it is the quality of these online interactions that distinguishes positive and negative mental health outcomes $[11 \bullet \bullet]$. For example, cyberbullying represents an obvious case whereby interactions with known peers can have a negative impact on a wide range of adolescent wellbeing outcomes: from lower self-esteem and mood to increased behavioural and emotional problems [53, 54]. Whilst this is an important area of research linking users' experiences of social media to mental health outcomes, it should be noted that very few young people experience bullying exclusively via social media platforms, and effect sizes for poor mental health associations are similar for cyberbullying and offline physical and relational bullying $[53,55]$. In contrast, positive online social interactions are associated with increased self-esteem and positive mental well-being, as well as decreased anxiety and depression, by providing social support and positive feedback $[13 \bullet \bullet, 56]$.

Clark and colleagues stress the importance of understanding this quality of social connection in their proposed interpersonal-connection-behaviours framework [11••], arguing that negative well-being outcomes are not inevitable, but depend on whether specific social media practices promote meaningful social connection. Social media practices that do focus on facilitating positive social connections can in fact offer a range of benefits to well-being. This perspective can help make sense of apparently contradictory findings based on frequency and duration of use. It can also accommodate new insight into individual differences, with recent evidence highlighting benefits for certain groups, whereby social media platforms can provide opportunities for positive social connection for individuals with a range of needs, including autism spectrum disorder and cerebral palsy $[57,58]$.

\section{Combining New Insights from Mental Health and Sleep Research}

Taking this broader perspective on social media use (moving beyond simply hours per day, to examine a range of relevant social and emotional aspects) has therefore brought valuable new insight to links with mental health, and we argue that this can offer similar benefits to sleep research and practice. For example, sleep researchers can build on existing evidence (which shows poorer sleep outcomes for those who use social media most, particularly at bedtime [59]), by further exploring the context and quality of this social media activity and seeking to better understand individuals' motivations and experiences of engaging with (and disengaging from) social media at night $[8,12]$.

\section{Current Issues and Challenges Facing Researchers}

We now consider some of the challenges currently facing researchers working to better understand links between social media use, sleep and mental health.

\section{Understanding Causality}

One common issue facing this field as a whole is the question of causality, as available research primarily uses crosssectional self-report data. A causal pathway from social media use to sleep is supported by evidence that implementing changes to bedtime media habits can improve sleep outcomes [45], highlighting the valuable contribution of experimental work. However, it is likely that this relationship is bidirectional, with some poor sleepers and those who have naturally later circadian preferences also turning to social media as a sleep aid or to pass time until they fall asleep [60, 61]. Similarly, whilst depressed individuals tend to interpret their social media interactions more negatively, certain online experiences (negative social comparison, seeking but not receiving support) can further negatively impact on mood, exacerbating symptoms for those with existing mental health problems [35, 36, 39, 62]. Existing studies consistently voice the need for future longitudinal work to examine temporal directionality and causality $[10,17,63]$. However, examining social media habits over time can present particular challenges when platforms, features and associated norms are continually shifting. 


\section{Rapidly Evolving Social Media Landscape}

An inevitable challenge in this fast-moving field is that technological developments outpace research, with continually evolving social media platforms, functionalities and associated norms. For example, the most popular platform to be studied in relation to anxiety and depression (as of June 2016) was Facebook [13••], which is now facing competition from other much more rapidly growing platforms, particularly among young people [18]. Even when a platform remains prevalent, its specific features evolve over time, facilitating shifts in the social expectations and norms for how people engage with social media. For example, with the introduction of "read receipts", users can now see when a message has been viewed, which contributes to perceived obligation to respond quickly $[8,9]$. Therefore, in this rapidly evolving social media landscape, research measures can quickly become outdated and even relatively recent findings may not generalise beyond the specific platforms and devices in vogue at the time of data collection $[2 \bullet, 64]$, as users' experiences are constantly changing. This presents a particular challenge for researchers responding to calls for longitudinal analysis in this area, since platform- or feature-specific measures can become outmoded during the course of the study.

\section{"Teenagers These Days"}

Much of the research in this area has focused on adolescents and young people. This is partly driven by concerns being voiced by policymakers, health professionals, educators and parents around the possible negative impact of social media on young people's health and well-being [65, 66]. These concerns are understandable, since adolescents and emerging adults must navigate an intense developmental stage, whilst managing high academic demands, during a period of increased risk for developing lifelong poor mental health [67, 68]. Adolescence has been described as bringing about a "Perfect Storm" of biological, psychosocial and societal factors that work together to produce short and ill-timed sleep for a majority of this population, where sleep need remains high $[22,69,70]$. Therefore, it is particularly relevant to understand how social media use, sleep and mental health interact in this adolescent population [17]. However, it is also important to ensure that available evidence does not neglect other age groups, as social media use is increasingly prevalent across all age groups [71], and its potentially changing implications for health and well-being across the lifespan remain a gap in current understanding [16].

Furthermore, as researchers and practitioners who are working with adolescent populations, it is important to be mindful of the language we use - and assumptions we make - concerning young people's social media habits. As a topic of current interest to a wide audience, research findings in this area are also being widely discussed in a public forum and as socially responsible researchers, we must consider the impact of our words. For example, research literature often approaches media use as a potential threat or harmful activity, using language around social media "addiction" and "problematic use" [10, 72-79], which can pathologise social media use despite insufficient evidence for considering it an addiction [80]. From our experience through research and engagement with adolescents and their teachers and parents, we have found that this type of language from adults is not constructive and often shuts down the potential for meaningful dialogue that can build shared inter-generational understanding. Therefore, making the adolescent voice heard in research literature, practice and decision-making is crucial. This ensures that we are best placed to support those young people who do perceive their experiences on social media as problematic, whilst avoiding applying unhelpful labels to those young people who devote considerable time to online social interactions, but who have positive experiences [81, 82].

\section{The Role of Measurement}

From our experience, we have come to consider the role of measurement in these various challenges facing researchers and practitioners, and now view it as a crucial issue to address as the field moves forward. Measurement is of critical importance to the research process and yet is often overlooked: poor quality measurement is surprisingly prevalent in published literature and can seriously undermine the conclusions of a study [83•]. We are heartened to see recent advances in exploring the context and experience of social media interactions in relation to sleep and mental health. However, we note that researchers across these fields have nonetheless been limited by the research measures available to them [25]. Across this research area, use of single-item non-validated measures (often of duration or frequency of use) is common [13••, 25]. Furthermore, available multi-item validated measures are often specific to one platform $[84,85]$ and/or pathologise social media use [86-88]. It is crucial to remember that the measurement tools available to researchers and clinicians limit the questions we can ask participants and patients, the conclusions we can draw and the recommendations we can make. Therefore, if we only ask about participants' and patients' daily duration of social media use or experience of "addictive" symptoms, then, we are limiting our understanding and discussions (as well as wider public dialogue), by missing insight into other relevant and more positive aspects of social media interactions. Furthermore, measurement is a key issue to address when aiming to maximise the relevance and longevity of current research in a rapidly evolving social media landscape (which can become particularly problematic in longitudinal work). The following section further discusses the issue of 
measurement as one of several recommendations that we offer as the field moves forward.

\section{Recommendations for Future Steps}

Having considered these challenges currently facing researchers, we now briefly highlight some selected recommendations as this field moves forward.

\section{Considering Available Measurement Tools}

High-quality measures that move beyond quantifying and pathologising observable behaviours are crucial to allow balanced and constructive dialogue in research and practice as we move forward. Having tools available to capture underlying issues (e.g. motivations for and experiences of online social interactions) allows us to build a more nuanced understanding and also improves the longevity of measures, as specific platforms and features rise and fall over time [11••]. In our current work, we have developed and validated a measure of difficulty disengaging from social media at night, whose content and wording is built from an adolescent perspective [8]. Moving forward, we urge others to consider the role of measurement in the research they produce and consume [83•], and to question how the tools they use guide (and constrain) the conclusions and recommendations they can make.

This applies to longitudinal and large cohort studies, where planning for the inclusion of a high-quality measure (that captures specifically relevant experiences of social media engagement for sleep or mental health) is crucial to maximise meaningful and useful conclusions from considerable investment of resources. Open datasets offer valuable potential for secondary analysis, particularly when applying powerful new analysis techniques to data from large representative cohorts [34]. However, the conclusions we can make are only as good as the questions asked of these samples, and with survey space often limiting large cohort surveys to single-item measures of "screen time" or daily social media use, it is important to interpret findings within the limits of what they can and cannot tell us. Here, a collaborative, multidisciplinary approach can maximise different expertise and perspectives to ensure appropriate survey coverage that fully captures components of social media use that are specifically relevant for different aspects of health and well-being.

\section{Combining Multiple Methodologies and Perspectives for a Holistic Understanding}

Of course, no single methodological or theoretical approach can ever provide the full story, and we stress the value of triangulating insight from multiple methodologies, theoretical perspectives and disciplines. This can help build a holistic understanding of how individuals' social media experiences fit within their overall health and well-being, considering interactive effects between positive and negative aspects of social media use, sleep and mental health. Recent work has started to consider these simultaneously, often positioning sleep as a mediator linking social media use to mental health outcomes [63, 89], with the potential for future work to consider alternative plausible models (including likely interactive effects) by examining temporal relationships. Future work can benefit by combining insights from multiple methods, including validated self-report measures; data-scraping techniques to gather objective social media activity data [90]; and rich indepth insight from qualitative methods that can explore users' motivations and experiences as well as differing generational perspectives [7, 8, 19]. Furthermore, a collaborative approach can maximise expertise of researchers and clinicians in different disciplines, and support ongoing efforts to improve understanding of sleep and mental health as two inextricably linked aspects of overall health and well-being [20].

\section{Posting Preprints}

Rapid developments in technological and social trends mean that even the very latest published research findings can quickly become outdated, as social media platforms (and norms for how people engage with them) continue to evolve during the time between data collection and publication [64]. One practical step that researchers can take to minimise this delay is posting preprints. This involves depositing a freely available manuscript in a dedicated online server (e.g. PsyArXiv) before peer review and publication in an academic journal (https://psyarxiv.com). Preprints offer a simple way to accelerate communication of new findings, with benefits for authors and the field as a whole [91], which can be especially valuable when studying rapidly evolving phenomena like social media use.

\section{Conclusions}

Having surveyed these recent advances and current challenges in this area of research and practice, our hope for the coming years is that the field as a whole embraces this shift towards a broader perspective on social media use: establishing a more nuanced, in-depth understanding of its unique social, emotional and cognitive aspects. Collaborative multidisciplinary approaches that triangulate insight from different methodologies and perspectives can help inform an integrated understanding of sleep and mental health in today's connected world.

Acknowledgements The authors would like to thank Shannon McNee for her helpful discussions on current social media and mental health research literature. 


\section{Compliance with Ethical Standards}

Conflict of Interest Holly Scott and Heather Cleland Woods each declare no conflict of interest.

Human and Animal Rights and Informed Consent This article does not contain any studies with human or animal subjects performed by any of the authors.

Open Access This article is distributed under the terms of the Creative Commons Attribution 4.0 International License (http:// creativecommons.org/licenses/by/4.0/), which permits unrestricted use, distribution, and reproduction in any medium, provided you give appropriate credit to the original author(s) and the source, provide a link to the Creative Commons license, and indicate if changes were made.

\section{References}

Papers of particular interest, published recently, have been highlighted as:

- Of importance

-• Of major importance

1. Cain N, Gradisar M. Electronic media use and sleep in school-aged children and adolescents: a review. Sleep Med. 2010;11(8):735-42. https://doi.org/10.1016/j.sleep.2010.02.006 Proposed a model of potential mechanisms linking electronic media use to sleep in young people, which has guided recent research and been further updated by Bartel and Gradisar in 2017.

2. Hale L, Guan S. Screen time and sleep among school-aged children and adolescents: a systematic literature review. Sleep Med Rev. 2015;21:50-8. https://doi.org/10.1016/j.smrv.2014.07.007 Provides systematic review of existing studies examining different types of screen use (smartphone, TV etc.) and sleep in young people, as of 2015.

3. Van den Bulck J. The effects of media on sleep. Adolesc Med. 2010;21(3):418-29 vii.

4. Thomée S. Mobile phone use and mental health. A review of the research that takes a psychological perspective on exposure. Int $\mathrm{J}$ Environ Res Public Health. 2018;15(12). https://doi.org/10.3390/ ijerph15122692.

5. Kappos AD. The impact of electronic media on mental and somatic children's health. Int J Hyg Environ Health. 2007;210(5):555-62. https://doi.org/10.1016/j.ijheh.2007.07.003.

6. Przybylski AK, Weinstein N. A large-scale test of the goldilocks hypothesis: quantifying the relations between digital-screen use and the mental well-being of adolescents. Psychol Sci. 2017;28(2):204 15. https://doi.org/10.1177/0956797616678438.

7. Fox J, Moreland JJ. The dark side of social networking sites: an exploration of the relational and psychological stressors associated with Facebook use and affordances. Comput Hum Behav. 2015;45: 168-76. https://doi.org/10.1016/j.chb.2014.11.083.

8. Scott H, Biello SM, Woods HC. Identifying drivers for bedtime social media use despite sleep costs: the adolescent perspective. Preprint: 12 Oct 2018. Retrieved from: https://doi.org/10.31234/osf.io/2xb36.

9. Mai LM, Freudenthaler R, Schneider FM, Vorderer P. "I know you've seen it!" Individual and social factors for users' chatting behavior on Facebook. Comput Hum Behav. 2015;49:296-302. https://doi.org/10.1016/j.chb.2015.01.074.

10. Bhat S, Pinto-Zipp G, Upadhyay H, Polos PG. "To sleep, perchance to tweet": in-bed electronic social media use and its associations with insomnia, daytime sleepiness, mood, and sleep duration in adults. Sleep Health. 2018;4(2):166-73. https://doi.org/10.1016/j. sleh.2017.12.004.

11.• Clark JL, Algoe SB, Green MC. Social network sites and well-being: the role of social connection. Curr Dir Psychol Sci. 2017;27(1):32-7. https://doi.org/10.1177/0963721417730833 Proposes a unifying "interpersonal-connection-behaviours" framework to make sense of apparently contradictory findings in fragmented literature on social media and well-being.

12. Scott H, Woods HC. Fear of missing out and sleep: cognitive behavioural factors in adolescents' nighttime social media use. J Adolesc. 2018;68:61-5. https://doi.org/10.1016/j.adolescence.2018.07.009.

13.• Seabrook EM, Kern ML, Rickard NS. Social networking sites, depression, and anxiety: a systematic review. JMIR Ment Health. 2016;3(4):e50. https://doi.org/10.2196/mental.5842 Comprehensively catalogues how each study operationalised social media use and whether they found positive, negative or non-significant associations with anxiety, depression and mental well-being.

14. Levenson JC, Shensa A, Sidani JE, Colditz JB, Primack BA. Social media use before bed and sleep disturbance among young adults in the United States: a nationally representative study. Sleep. 2017;40(9):zsx113-zsx. https://doi.org/10.1093/sleep/zsx113.

15. Screen time guidelines need to be built on evidence, not hype. The Guardian, 6 Jan 2017. Retrieved from: https://www.theguardian. $\mathrm{com} / \mathrm{science} /$ headquarters/2017/jan/06/screen-time-guidelinesneed-to-be-built-on-evidence-not-hype. Accessed 11 July 2019. Open letter by an international group of scientists, arguing against "unhelpful" focus on "simplistic and arguably meaningless" concept of generic screen time, and calling for improved understanding of context and content.

16. Exelmans L, Scott H. Social Media Use and Sleep Quality among Adults: The Role of Gender, Age and Social Media Checking Habit. Preprint: 17 April 2019. https://doi.org/10.31234/osf.io/eqxdh

17. Woods HC, Scott H. \#Sleepyteens: social media use in adolescence is associated with poor sleep quality, anxiety, depression and low self-esteem. J Adolesc. 2016;51:41-9. https://doi.org/10.1016/j. adolescence.2016.05.008.

18. Smith A, Anderson M. Social Media Use in 2018. Pew Research Center; 2018. Retrieved from: https://www.pewinternet.org/2018/ 03/01/social-media-use-in-2018/.

19. Thomee S, Dellve L, Harenstam A, Hagberg M. Perceived connections between information and communication technology use and mental symptoms among young adults - a qualitative study. BMC Public Health. 2010;10:66. https://doi.org/10.1186/1471-2458-1066.

20. Reynolds CF 3rd, O'Hara R. DSM-5 sleep-wake disorders classification: overview for use in clinical practice. Am J Psychiatry. 2013;170(10):1099-101. https://doi.org/10.1176/appi.ajp.2013. 13010058

21. American Psychiatric Association. Diagnostic and Statistical Manual of Mental Disorders. 5th ed. Washington D.C.: 2013.

22. Owens J. Insufficient sleep in adolescents and young adults: an update on causes and consequences. Pediatrics. 2014;134(3): E921-E32. https://doi.org/10.1542/peds.2014-1696.

23. Hafner M, Stepanek M, Taylor J, Troxel WM, Stolk CV. Why sleep matters - the economic costs of insufficient sleep: a cross-country comparative analysis. Santa Monica, CA: RAND Corporation, 2016. Retrieved from: https://www.rand.org/pubs/research reports/RR1791.html

24. Sobocki P, Jonsson B, Angst J, Rehnberg C. Cost of depression in Europe. J Ment Health Policy Econ. 2006;9(2):87-98.

25. Jenkins-Guarnieri MA, Wright SL, Johnson B. Development and validation of a social media use integration scale. Psychol Pop Media Cult. 2013;2(1):38-50. https://doi.org/10.1037/a0030277. 
26. Levenson JC, Shensa A, Sidani JE, Colditz JB, Primack BA. The association between social media use and sleep disturbance among young adults. Prev Med. 2016;85(Supplement C):36-41. https:// doi.org/10.1016/j.ypmed.2016.01.001.

27.• Bartel K, Gradisar M. New directions in the link between technology use and sleep in young people. In: Nevšímalová $\mathrm{S}$, Bruni $\mathrm{O}$, editors. Sleep disorders in children. Cham: Springer International Publishing; 2017. p. 69-80. Discusses recent developments in research on technology use and sleep in young people, which updates Cain and Gradisar's 2010 model of mechanisms.

28. Van den Bulck J. Television viewing, computer game playing, and Internet use and self-reported time to bed and time out of bed in secondary-school children. Sleep. 2004;27(1):101-4.

29. Van den Bulck J. Text messaging as a cause of sleep interruption in adolescents, evidence from a cross-sectional study. J Sleep Res. 2003;12(3):263.

30. Exelmans L, Van den Bulck J. Bedtime, shuteye time and electronic media: sleep displacement is a two-step process. J Sleep Res. 2017;26(3):364-70. https://doi.org/10.1111/jsr.12510.

31. Chang A-M, Aeschbach D, Duffy JF, Czeisler CA. Evening use of light-emitting eReaders negatively affects sleep, circadian timing, and next-morning alertness. Proc Natl Acad Sci. 2015;112(4): 1232-7. https://doi.org/10.1073/pnas.1418490112.

32. Exelmans L, Van den Bulck J. Binge viewing, sleep, and the role of pre-sleep arousal. J Clin Sleep Med. 2017;13(8):1001-8. https:// doi.org/10.5664/jcsm.6704.

33. Best P, Manktelow R, Taylor B. Online communication, social media and adolescent wellbeing: a systematic narrative review. Child Youth Serv Rev. 2014;41:27-36. https://doi.org/10.1016/j. childyouth.2014.03.001

34. Orben A, Przybylski AK. The association between adolescent wellbeing and digital technology use. Nat Hum Behav. 2019;3(2):17382. https://doi.org/10.1038/s41562-018-0506-1.

35. Frison E, Eggermont S. The impact of daily stress on adolescents' depressed mood: the role of social support seeking through Facebook. Comput Hum Behav. 2015;44:315-25. https://doi.org/ 10.1016/j.chb.2014.11.070

36. Park J, Lee DS, Shablack H, Verduyn P, Deldin P, Ybarra O, et al. When perceptions defy reality: the relationships between depression and actual and perceived Facebook social support. J Affect Disord. 2016;200:37-44. https://doi.org/10.1016/j.jad.2016.01.048

37. McCloskey W, Iwanicki S, Lauterbach D, Giammittorio DM, Maxwell K. Are Facebook "friends" helpful? Development of a Facebook-based measure of social support and examination of relationships among depression, quality of life, and social support. Cyberpsychol Behav Soc Netw. 2015;18(9):499-505. https://doi. org/10.1089/cyber.2014.0538.

38. McNee S, Woods HC. Pre-sleep Cognitive Influence of Night-time Social Media Use and Social Comparison Behaviour in Young Women. Preprint: 12 February 2019. Retrieved from: https://doi. org/10.31234/osf.io/n9txa.

39. Appel H, Crusius J, Gerlach AL. Social comparison, envy, and depression on Facebook: a study looking at the effects of high comparison standards on depressed individuals. J Soc Clin Psychol. 2015;34(4): 277-89. https://doi.org/10.1521/jscp.2015.34.4.277.

40. Primack BA, Karim SA, Shensa A, Bowman N, Knight J, Sidani JE. Positive and negative experiences on social media and perceived social isolation. Am J Health Promot. 2019: 0890117118824196. https://doi.org/10.1177/0890117118824196.

41. Orzech KM, Grandner MA, Roane BM, Carskadon MA. Digital media use in the $2 \mathrm{~h}$ before bedtime is associated with sleep variables in university students. Comput Hum Behav. 2016;55:43-50.

42. Harbard E, Allen NB, Trinder J, Bei B. What's keeping teenagers up? Prebedtime behaviors and actigraphy-assessed sleep over school and vacation. J Adolesc Health. 2016;58(4):426-32. https://doi.org/10.1016/j.jadohealth.2015.12.011.
43. Vorderer P, Kromer N, Schneider FM. Permanently online - permanently connected: explorations into university students' use of social media and mobile smart devices. Comput Hum Behav. 2016;63:694-703. https://doi.org/10.1016/j.chb.2016.05.085.

44. Przybylski AK, Murayama K, DeHaan CR, Gladwell V. Motivational, emotional, and behavioral correlates of fear of missing out. Comput Hum Behav. 2013;29(4):1841-8. https://doi.org/ 10.1016/j.chb.2013.02.014.

45. Bartel K, Scheeren R, Gradisar M. Altering adolescents' pre-bedtime phone use to achieve better sleep health. Health Commun. 2018;34:17. https://doi.org/10.1080/10410236.2017.1422099.

46. Houghton S, Hunter SC, Rosenberg M, Wood L, Zadow C, Martin $\mathrm{K}$, et al. Virtually impossible: limiting Australian children and adolescents daily screen based media use. BMC Public Health. 2015;15(1):5. https://doi.org/10.1186/1471-2458-15-5.

47. Lin LY, Sidani JE, Shensa A, Radovic A, Miller E, Colditz JB, et al. Association between social media use and depression among U.S. young adults. Depress Anxiety. 2016;33(4):323-31. https://doi.org/ 10.1002/da.22466.

48. Banjanin N, Banjanin N, Dimitrijevic I, Pantic I. Relationship between internet use and depression: focus on physiological mood oscillations, social networking and online addictive behavior. Comput Hum Behav. 2015;43:308-12. https://doi.org/10.1016/j. chb.2014.11.013.

49. Shaw AM, Timpano KR, Tran TB, Joormann J. Correlates of Facebook usage patterns: the relationship between passive Facebook use, social anxiety symptoms, and brooding. Comput Hum Behav. 2015;48:57580. https://doi.org/10.1016/j.chb.2015.02.003.

50. Pittman M, Reich B. Social media and loneliness: why an Instagram picture may be worth more than a thousand Twitter words. Comput Hum Behav. 2016;62:155-67. https://doi.org/10.1016/j.chb.2016. 03.084.

51. Yang C-C. Instagram use, loneliness, and social comparison orientation: interact and browse on social media, but don't compare. Cyberpsychol Behav Soc Netw. 2016;19(12):703-8. https://doi. org/10.1089/cyber.2016.0201.

52. Lup K, Trub L, Rosenthal L. Instagram \#Instasad?: exploring associations among Instagram use, depressive symptoms, negative social comparison, and strangers followed. Cyberpsychol Behav Soc Netw. 2015;18(5):247-52. https://doi.org/10.1089/cyber.2014. 0560 .

53. Wolke D, Lee K, Guy A. Cyberbullying: a storm in a teacup? Eur Child Adolesc Psychiatry. 2017;26(8):899-908. https://doi.org/10. 1007/s00787-017-0954-6.

54. Kowalski RM, Giumetti GW, Schroeder AN, Lattanner MR. Bullying in the digital age: a critical review and meta-analysis of cyberbullying research among youth. Psychol Bull. 2014;140(4): 1073-137. https://doi.org/10.1037/a0035618.

55. Przybylski AK, Bowes L. Cyberbullying and adolescent well-being in England: a population-based cross-sectional study. Lancet Child Adolesc Health. 2017;1(1):19-26. https://doi.org/10.1016/S23524642(17)30011-1.

56. Valkenburg PM, Peter J, Schouten AP. Friend networking sites and their relationship to adolescents' well-being and social self-esteem. Cyberpsychol Behav. 2006;9(5):584-90. https://doi.org/10.1089/ cpb.2006.9.584.

57. Kuo MH, Orsmond GI, Coster WJ, Cohn ES. Media use among adolescents with autism spectrum disorder. Autism. 2013;18(8): 914-23. https://doi.org/10.1177/1362361313497832.

58. Caron J, Light J. "Social media has opened a world of 'open communication:"” experiences of adults with cerebral palsy who use augmentative and alternative communication and social media. Augment Altern Commun (Baltimore, Md : 1985). 2016;32(1):25-40. https:// doi.org/10.3109/07434618.2015.1052887.

59. Scott H, Biello SM, Woods HC. Social media use and adolescent sleep outcomes: cross-sectional findings from the UK Millennium 
Cohort Study. Preprint: 19 Feb 2019. Retrieved from: https://doi. org/10.31234/osf.io/z7kpf.

60. Exelmans L, Van den Bulck J. The use of media as a sleep aid in adults. Behav Sleep Med. 2016;14(2):121-33. https://doi.org/10. 1080/15402002.2014.963582.

61. Tavernier R, Willoughby T. Sleep problems: predictor or outcome of media use among emerging adults at university? J Sleep Res. 2014;23(4):389-96. https://doi.org/10.1111/jsr.12132.

62. Feinstein BA, Hershenberg R, Bhatia V, Latack JA, Meuwly N, Davila J. Negative social comparison on Facebook and depressive symptoms: rumination as a mechanism. US: Educational Publishing Foundation; 2013. p. 161-70.

63. Li X, Buxton OM, Lee S, Chang AM, Berger LM, Hale L. Sleep mediates the association between adolescent screen time and depressive symptoms. Sleep Med. 2019;57:51-60. https://doi.org/10. 1016/j.sleep.2019.01.029.

64. Lancet T. Social media, screen time, and young people's mental health. Lancet. 2019;393(10172):611. https://doi.org/10.1016/ S0140-6736(19)30358-7.

65. UK House of Commons Science and Technology Committee. Impact of social media and screen-use on young people's health. 2019. Retrieved from: https://publications.parliament.uk/pa/ $\mathrm{cm} 201719 / \mathrm{cmselect} / \mathrm{cmsctech} / 822 / 82202 . \mathrm{htm}$.

66. Screen-based lifestyle harms children's health. The Guardian, 25 Dec 2016. Retrieved from: https://www.theguardian.com/ education $/ 2016 / \mathrm{dec} / 25 /$ screen-based-lifestyle-harms-health-ofchildren. Accessed 11 July 2019.

67. Orth U, Maes J, Schmitt M. Self-esteem development across the life span: a longitudinal study with a large sample from Germany. Dev Psychol. 2015;51(2):248-59. https://doi.org/10.1037/a0038481.

68. McLaughlin KA, King K. Developmental trajectories of anxiety and depression in early adolescence. J Abnorm Child Psychol. 2015;43(2):311-23. https://doi.org/10.1007/s10802-014-9898-1.

69. Carskadon MA. Sleep in adolescents: the perfect storm. Pediatr Clin N Am. 2011;58(3):637-47. https://doi.org/10.1016/j.pcl. 2011.03.003.

70. Crowley SJ, Wolfson AR, Tarokh L, Carskadon MA. An update on adolescent sleep: new evidence informing the perfect storm model. J Adolesc. 2018;67:55-65. https://doi.org/10.1016/j.adolescence. 2018.06.001.

71. Greenwood S, Perrin A, Duggan M. Social media update. Pew Research Center; 2016. Retrieved from: https://www.pewinternet. org/2016/11/11/social-media-update-2016/.

72. Vernon L, Modecki KL, Barber BL. Tracking effects of problematic social networking on adolescent psychopathology: the mediating role of sleep disruptions. J Clin Child Adolesc Psychol. 2017;46(2):269-83. https://doi.org/10.1080/15374416.2016. 1188702 .

73. An J, Sun Y, Wan Y, Chen J, Wang X, Tao F. Associations between problematic internet use and adolescents' physical and psychological symptoms: possible role of sleep quality. J Addict Med. 2014;8(4): 282-7. https://doi.org/10.1097/adm.0000000000000026.

74. Andreassen CS, Pallesen S, Griffiths MD. The relationship between addictive use of social media, narcissism, and self-esteem: findings from a large national survey. Addict Behav. 2017;64(Supplement C):287-93. https://doi.org/10.1016/j.addbeh.2016.03.006.

75. Bányai F, Zsila Á, Király O, Maraz A, Elekes Z, Griffiths MD, et al. Problematic social media use: results from a large-scale nationally representative adolescent sample. PLoS One. 2017;12(1):e0169839. https://doi.org/10.1371/journal.pone.0169839.

76. Elhai JD, Levine JC, Dvorak RD, Hall BJ. Fear of missing out, need for touch, anxiety and depression are related to problematic smartphone use. Comput Hum Behav. 2016;63:509-16. https:// doi.org/10.1016/j.chb.2016.05.079.

77. Elhai JD, Levine JC, Dvorak RD, Hall BJ. Non-social features of smartphone use are most related to depression, anxiety and problematic smartphone use. Comput Hum Behav. 2017;69:7582. https://doi.org/10.1016/j.chb.2016.12.023.

78. Rozgonjuk D, Levine JC, Hall BJ, Elhai JD. The association between problematic smartphone use, depression and anxiety symptom severity, and objectively measured smartphone use over one week. Comput Hum Behav. 2018;87:10-7. https://doi.org/10.1016/ j.chb.2018.05.019.

79. Satici SA, Uysal R. Well-being and problematic Facebook use. Comput Hum Behav. 2015;49:185-90. https://doi.org/10.1016/j. chb.2015.03.005.

80. Billieux J, Maurage P, Lopez-Fernandez O, Kuss D, Griffiths M. Can Disordered Mobile Phone Use Be Considered a Behavioral Addiction? An Update on Current Evidence and a Comprehensive Model for Future Research. Current Addiction Reports. 2015;2: 156. https://doi.org/10.1007/s40429-015-0054-y.

81. Tzavela EC, Karakitsou C, Dreier M, Mavromati F, Wölfling K, Halapi $\mathrm{E}$, et al. Processes discriminating adaptive and maladaptive Internet use among European adolescents highly engaged online. J Adolesc. 2015;40:34 47. https://doi.org/10.1016/j.adolescence.2014.12.003.

82. Tzavela EC, Karakitsou C, Halapi E, Tsitsika AK. Adolescent digital profiles: a process-based typology of highly engaged internet users. Comput Hum Behav. 2017;69:246-55. https://doi.org/10. 1016/j.chb.2016.11.032.

83. Flake JK, Pek J, Hehman E. Construct validation in social and personality research: current practice and recommendations. Soc Psychol Personal Sci. 2017;8(4):370-8. https://doi.org/10.1177/ 1948550617693063 Provides useful recommendations to guide researchers in evaluating the validity of measures when conducting and reading empirical studies.

84. Ellison NB, Steinfield C, Lampe C. The benefits of Facebook "friends": social capital and college students' use of online social network sites. J Comput-Mediat Commun. 2007;12(4):1143-68.

85. Ross C, Orr ES, Sisic M, Arseneault JM, Simmering MG, Orr RR. Personality and motivations associated with Facebook use. Comput Hum Behav. 2009;25(2):578-86. https://doi.org/10.1016/j.chb. 2008.12.024.

86. van den Eijnden RJJM, Lemmens JS, Valkenburg PM. The social media disorder scale. Comput Hum Behav. 2016;61:478-87. https://doi.org/10.1016/j.chb.2016.03.038.

87. Andreassen CS, Torsheim T, Brunborg GS, Pallesen S. Development of a Facebook Addiction Scale. Psychol Rep. 2012;110(2):501-17. https://doi.org/10.2466/02.09.18.pr0.110.2. 501-517.

88. Holmgren HG, Coyne SM. Can't stop scrolling!: pathological use of social networking sites in emerging adulthood. Addict Res Theory. 2017;25(5):375-82. https://doi.org/10.1080/16066359. 2017.1294164.

89. Kelly Y, Zilanawala A, Booker C, Sacker A. Social media use and adolescent mental health: findings from the UK Millennium Cohort Study. EClinicalMedicine. 2018;6:59-68. https://doi.org/10.1016/j. eclinm.2018.12.005.

90. Chen L, Gong T, Kosinski M, Stillwell D, Davidson RL. Building a profile of subjective well-being for social media users. PLoS One. 2017;12(11):e0187278. https://doi.org/10.1371/journal.pone. 0187278 .

91. Sarabipour S, Debat HJ, Emmott E, Burgess SJ, Schwessinger B, Hensel Z. On the value of preprints: an early career researcher perspective. PLoS Biol. 2019;17(2):e3000151. https://doi.org/10. 1371/journal.pbio.3000151.

Publisher's Note Springer Nature remains neutral with regard to jurisdictional claims in published maps and institutional affiliations. 